\title{
Drinking Water Arsenic Contamination, Skin Lesions, and Malignancies: A Systematic Review of the Global Evidence
}

\author{
Margaret R. Karagas • Anala Gossai • Brandon Pierce • \\ Habibul Ahsan
}

Published online: 3 March 2015

(C) Springer International Publishing AG 2015

\begin{abstract}
Skin lesions and cancer are known manifestations of chronic exposure to arsenic contaminated drinking water. Epidemiologic data primarily comes from regions with exposures 1-2 orders of magnitude above the current World Health Organization (WHO) guidelines of $10 \mu \mathrm{g} / \mathrm{L}$. Emerging evidence indicates that more common exposures may also be related to both noncancerous and cancerous changes to the skin. In this review, we focus on the body of epidemiologic literature that encompasses exposures within the WHO guidelines, excluding studies that lacked individual exposure estimates and case reports. For skin lesions and skin cancers, 15 and 10 studies were identified that met our criteria, respectively. For skin lesions, a consistent dose-response relationship with water arsenic has been observed, with increased risk evident at low- to moderate-dose exposure. Of the larger studies of specific histologic types of skin cancers, although with differing exposure definitions, there was evidence of doserelated relationships with both basal cell carcinomas and squamous cell carcinomas. The effect of arsenic exposure on skin lesion risk is likely modified by genetic variants that influence arsenic metabolism. Accumulating evidence suggests that arsenic may increase risk of skin lesions and skin cancers at levels not previously considered harmful, and that genetic factors may influence risk.
\end{abstract}

This article is part of the Topical collection on Water and Health

M. R. Karagas · A. Gossai

Department of Epidemiology, Geisel School of Medicine, Dartmouth

College, Hanover, NH, USA

M. R. Karagas $(\bowtie)$

1 Medical Center Drive, 7927 Rubin Building, Lebanon, NH 03756,

USA

e-mail: Margaret.Karagas@Dartmouth.edu

B. Pierce $\cdot$ H. Ahsan

Department of Public Health Sciences, University of Chicago, 5841

S. Maryland Ave, MC 2007, Chicago, IL 60637, USA
Keywords Arsenic $\cdot$ Total arsenic $\cdot$ Inorganic arsenic . Organic arsenic $\cdot$ Arsenic metabolism $\cdot$ Skin cancer . Basal cell carcinoma $\cdot$ Squamous cell carcinoma . Skin lesions $\cdot$ Low dose exposure $\cdot$ Drinking water exposure

\section{Introduction}

The skin is a sentinel organ for the effects of chronic arsenic exposure, including exposure through drinking water. In particular, arsenical skin lesions are the hallmark of chronic arsenic poisoning and typically begin to appear within a few years of exposure [1,2]. Individuals with these lesions are considered to be at higher risk for skin and other cancers [3]. Skin lesions typically begin with a diffuse hyper-pigmentation (often with hypopigmented spots) of the chest, neck, and trunk, with concomitant or later appearance of hyperkeratosis of palms and soles [4, 5].

According to the International Agency for Research on Cancer (IARC), there is sufficient human evidence of arsenic's skin carcinogenicity [6-8]. The earliest links came from patients treated for psoriasis and other ailments with arseniccontaining compounds (eg, Fowler's Solution containing $1 \%$ potassium arsenite) and later in German vintners exposed to inorganic arsenic (iAs)-pesticides [8]. Furthermore, several regions with highly arsenic-contaminated drinking water have reported cases of skin cancers (reviewed in IARC, 2004 [7]). In 1968, Tseng and colleagues published an ecologic analysis of village drinking water and skin cancer prevalence based on a household survey in the southwest of Taiwan's Blackfoot endemic region, where residents consumed arseniccontaminated artesian well water for many decades [9]. A clear increasing trend in skin cancer prevalence was observed from low $(<300 \mu \mathrm{g} / \mathrm{L})$, medium $(300-600 \mu \mathrm{g} / \mathrm{L})$ and high 
$(>600 \mu \mathrm{g} / \mathrm{L})$ arsenic areas of $2.6,10.1$, and 21.4 cases per 1000 persons - demonstrating an 8 -fold difference from the highest to lowest category of arsenic exposure. Elevated standardized mortality ratios of skin cancer both in the southwest of Taiwan and in a northern region of Chile served by an arsenic contaminated water supply (of up to $870 \mu \mathrm{g} / \mathrm{L}$ ) further pointed to excess skin cancers among populations exposed to high drinking water concentrations of arsenic $[7,8]$. The characteristics of arsenic-associated skin tumors include squamous cell carcinomas (SCC) (including Bowen's disease) arising in keratoses and multiple basal cell carcinomas (BCC) [10-12]. While there is an intriguing report of an association between arsenic exposure and melanoma skin cancer in a US population [13], this association has not been evaluated in other populations and it has not yet been deemed causal.

Further, it has been hypothesized that individuals vary in their susceptibility to arsenic toxicity due in part to interindividual differences in inherited genetic factors (with other environmental, nutritional, and/or lifestyle susceptibility factors likely to play a role). For instance, genetic variants that influence an individual's capacity to metabolize and excrete arsenic could impact an individual's body burden of arsenic and also affect an individual's susceptibility to exposure. One example of this phenomenon is the 10q24.32 region, which contains the AS3MT gene (arsenite methyltransferase). There are multiple variants in this region that show independent association with relative concentrations of arsenic metabolites in urine, suggesting they impact arsenic metabolism efficiency and toxicity risk $[14,15,16 \bullet, 17,18]$.

An outstanding question is whether skin lesions and cancers occur globally in populations with lower, more common levels of exposure to arsenic in drinking water, including those around the current WHO drinking water guideline of $10 \mu \mathrm{g} / \mathrm{L}$ [19]. The majority of the skin lesions are potentially reversible, except for very advanced keratotic nodules, which persist for decades in some individuals. Moreover, it is as yet uncertain how risks may be altered by individual differences in arsenic metabolism that may be particularly relevant to populations with lower exposure levels. As this emerging literature has not been extensively reviewed, we focus here on epidemiologic case-control and cohort studies of skin lesions and malignancies characterized by individual estimates of exposure to arsenic through drinking water or biomarkers of arsenic exposure that correlate with drinking water exposure at exposures levels encompassing the WHO guideline value. Our review does not encompass laboratory experiments or mechanistic-based studies.

\section{Methods}

To systematically review the epidemiologic literature on skin lesions and skin cancer, we searched for articles published and catalogued in PubMed prior to July 2014. Study designs other than case-control or cohort studies (eg, studies lacking individual exposure estimates and case reports) were excluded from this review. We did not consider studies based on skin cancer mortality as an endpoint [20-22] as these conditions are not typically fatal and do not accurately reflect the incidence of these outcomes. Further, we removed studies that only included exposure above $100 \mu \mathrm{g} / \mathrm{L}$. Thus, studies exclusively reporting on high levels of arsenic exposure (eg, in regions in Taiwan or South America) were omitted [9, 23-26]. Studies that used individual estimates from drinking water arsenic measurements or a biomarker known to correlate with drinking water arsenic (eg, urine or toenails [27, 28]) were included in the review, but those which considered arsenic-containing medicines were excluded [29]. Occupational arsenic exposure, disease-surrogates (eg, when Blackfoot disease was used to define exposure), or exposures classified solely by self-report were also excluded. Studies that did not report original research; only presented effect estimates modified by some other factor; were carried out in vitro, in animal models, or in human tissues to primarily study biological mechanisms were not considered in this review. In addition to articles identified through PubMed, we searched reviews of arsenic and skin lesions or cancer (including IARC 2004 and 2009 [7, 8], EFSA 2009 [30], and NAS 2014 [31]) as well as the reference lists of the articles we reviewed to identify any additional articles. Two authors reviewed the papers for inclusion/exclusion criteria and questions were resolved by consensus.

For skin lesions, we searched PubMed for the words 'arsenic' and 'skin lesions' or 'skin lesion' or 'dermal lesion'. In total, 273 publications were returned by the search, of which 22 publications met our inclusion criteria. For multiple studies from the same cohort, we presented the publication with the longest follow-up provided it included results with detailed exposure information. Of the 22 publications, 8 reported on the same study, so only 1 [32•] of the 8 publications was presented (the other 7 were identified in the comments section of Table 1). In the end, 15 publications were reviewed (Fig. 1a).

For skin cancers, we reviewed original research relevant to nonmelanoma skin (NMSC) or keratinocyte cancers (ie, squamous cell and basal cell carcinomas of the skin-including Bowen's disease), as arsenic is known to cause these malignancies. Melanoma was excluded from this review, as so far very few studies have evaluated the association between arsenic and melanoma. In PubMed, we searched for the words 'arsenic' and 'nonmelanoma skin cancer' or 'SCC' or 'BCC' or 'squamous cell carcinoma' or 'basal cell carcinoma' or 'keratinocyte cancer'. In total, 156 publications were returned by the search and 10 publications were identified that met our criteria (Fig. 1b). 


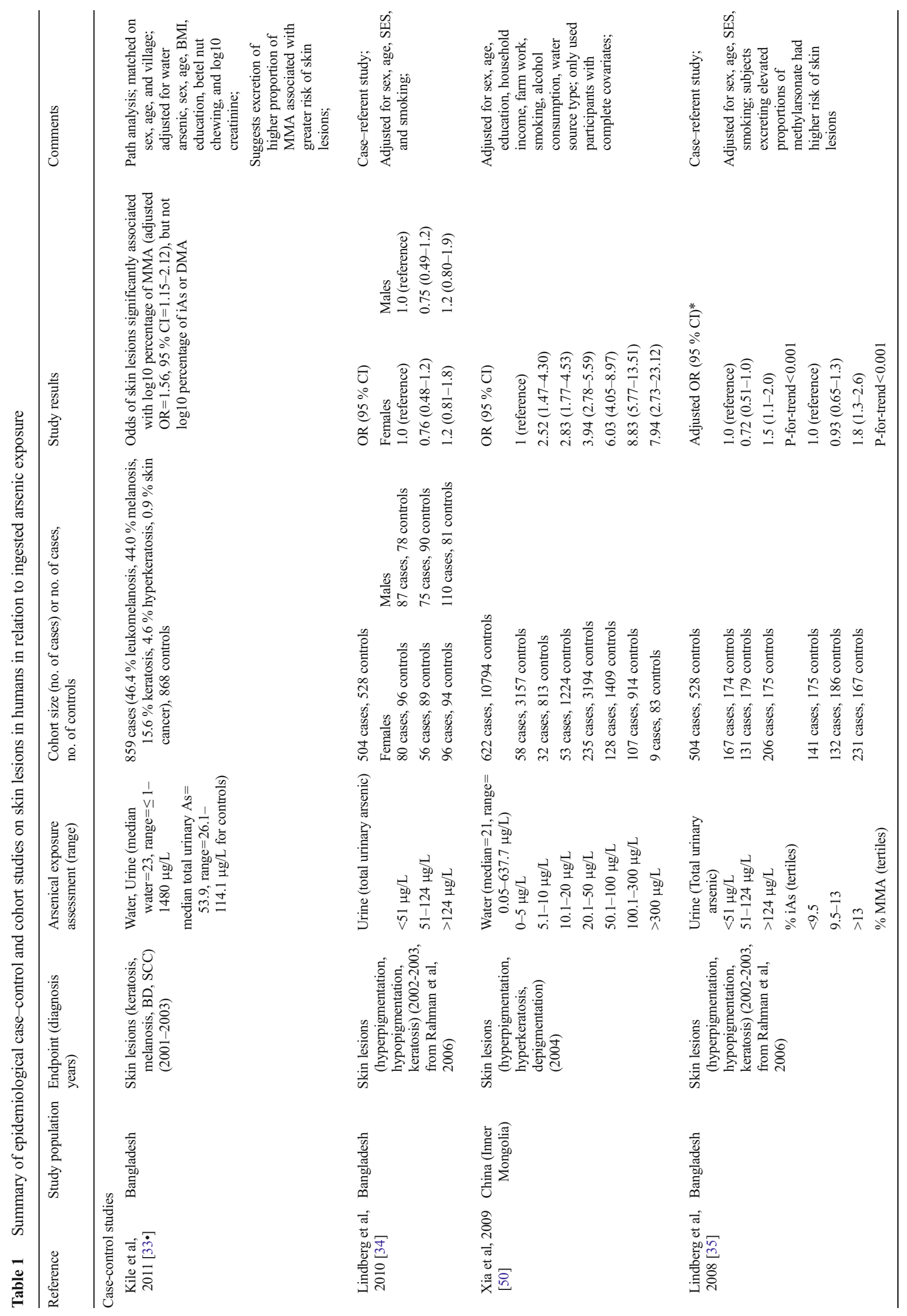




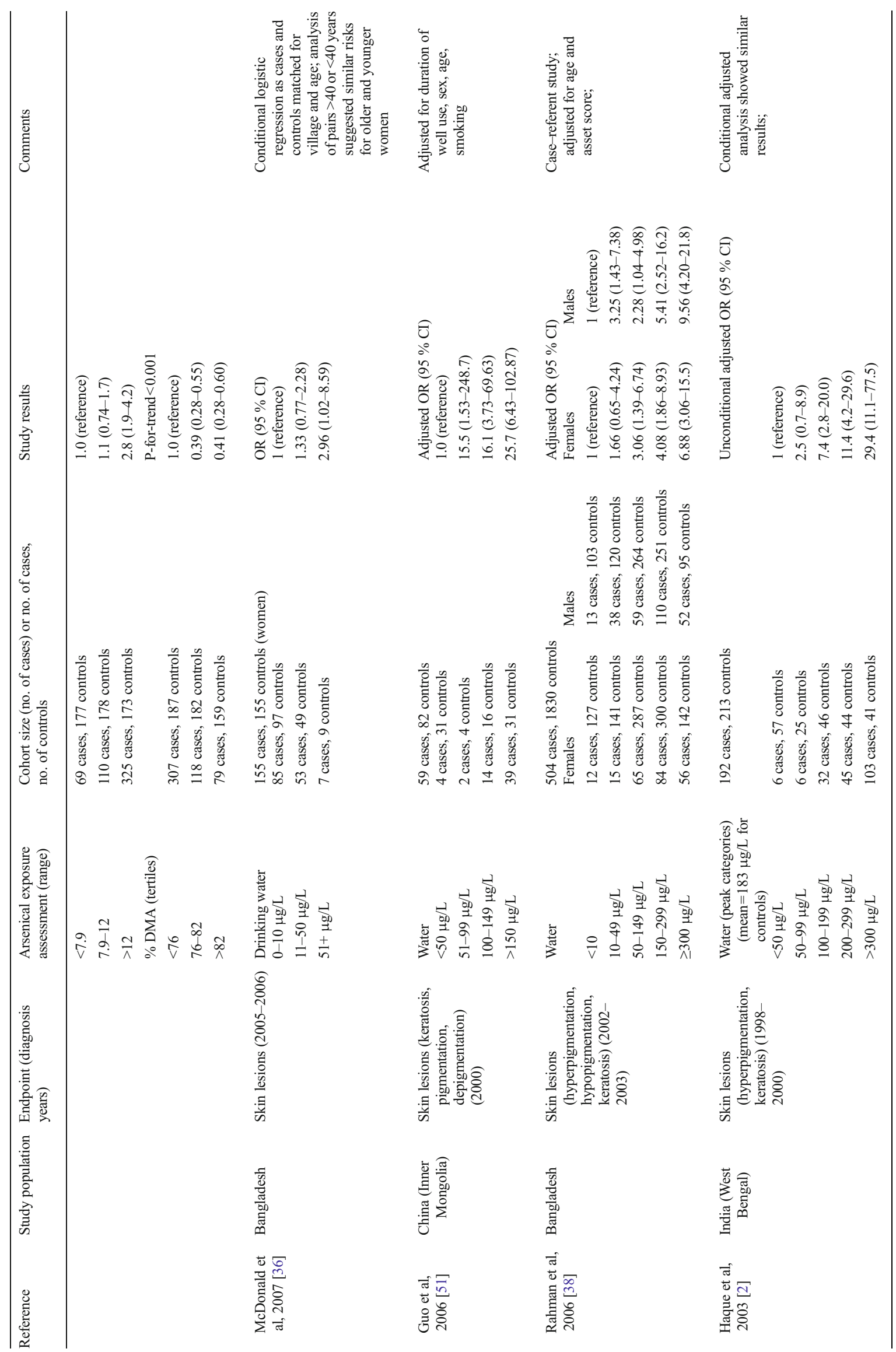




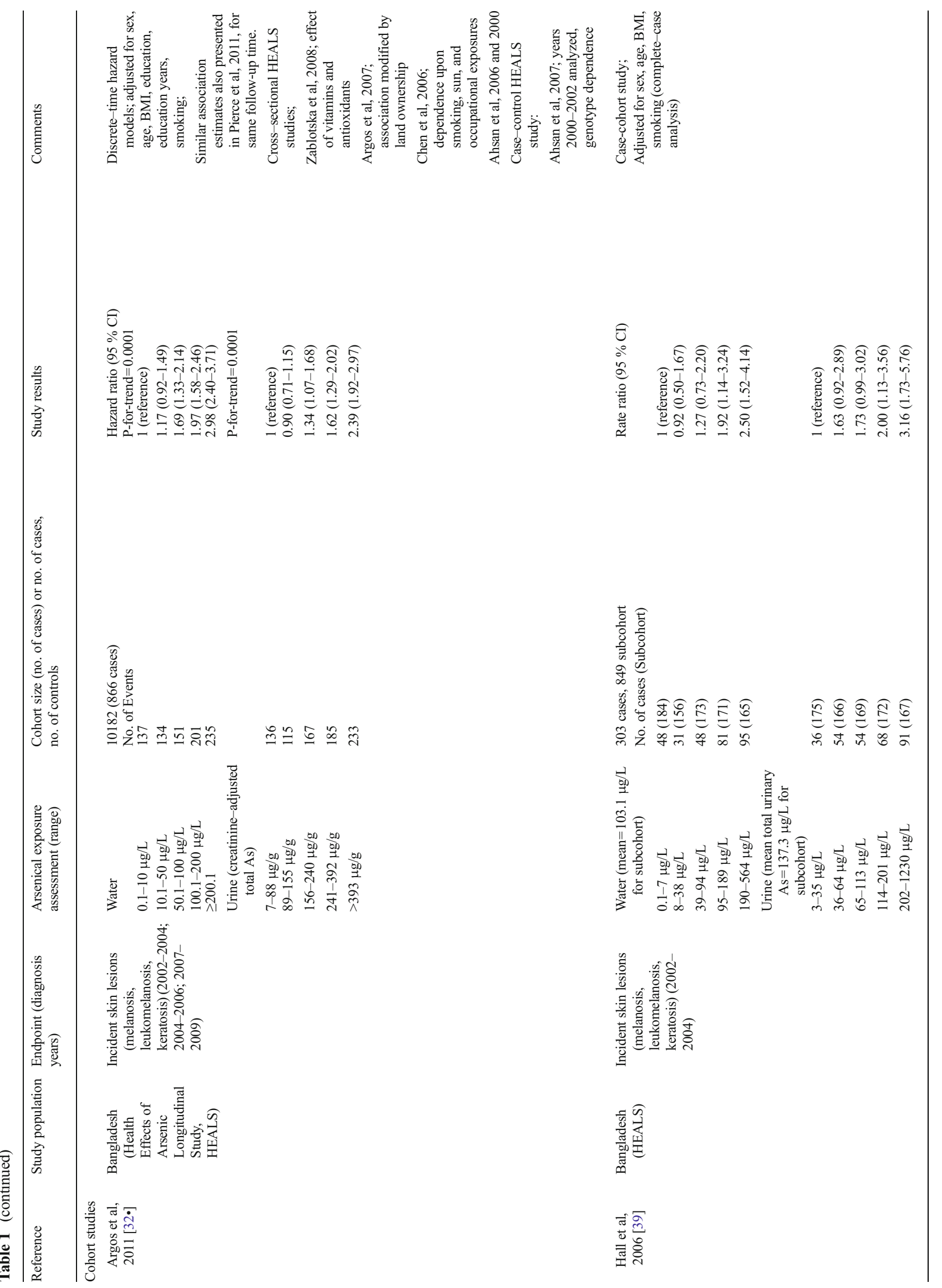




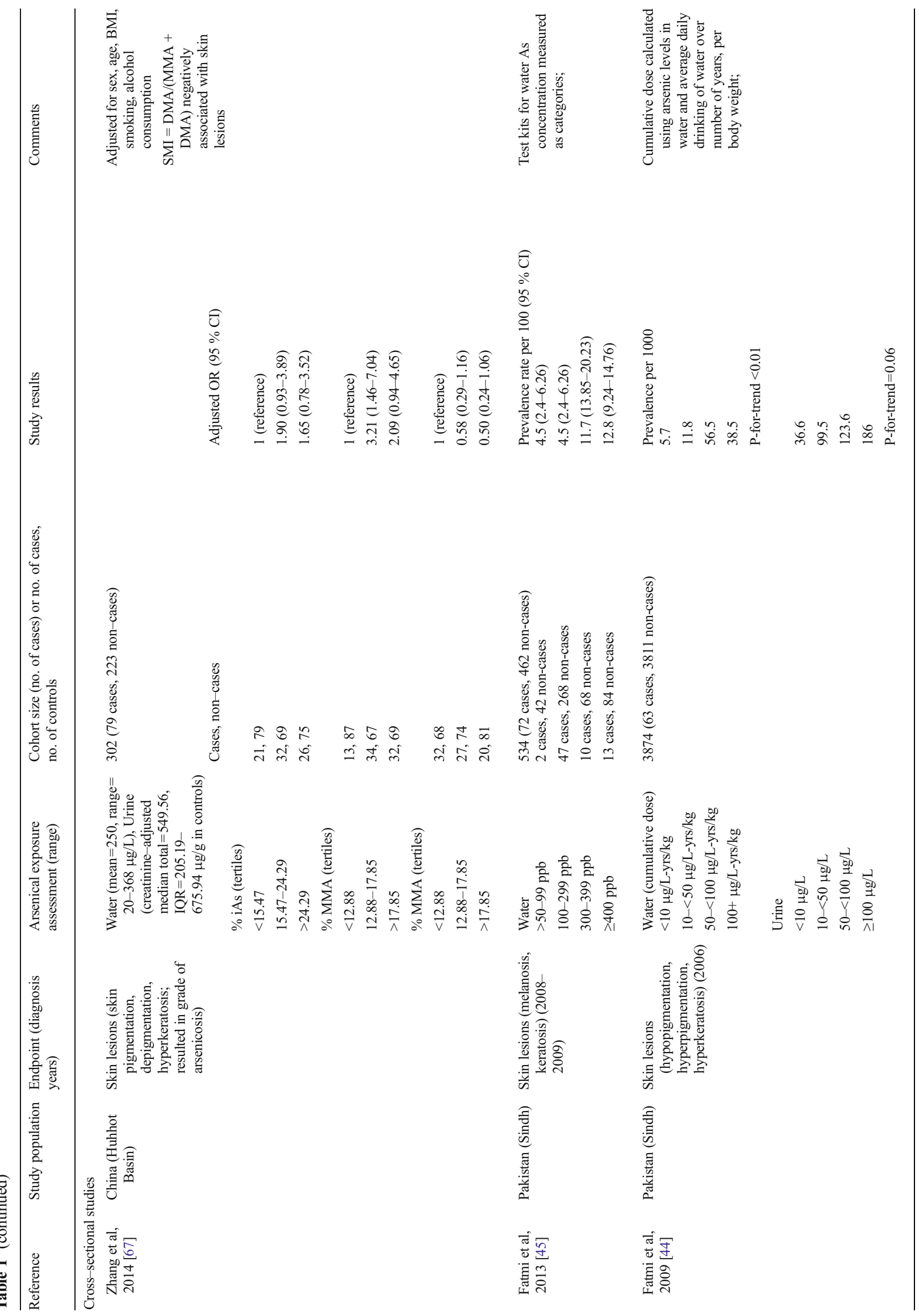




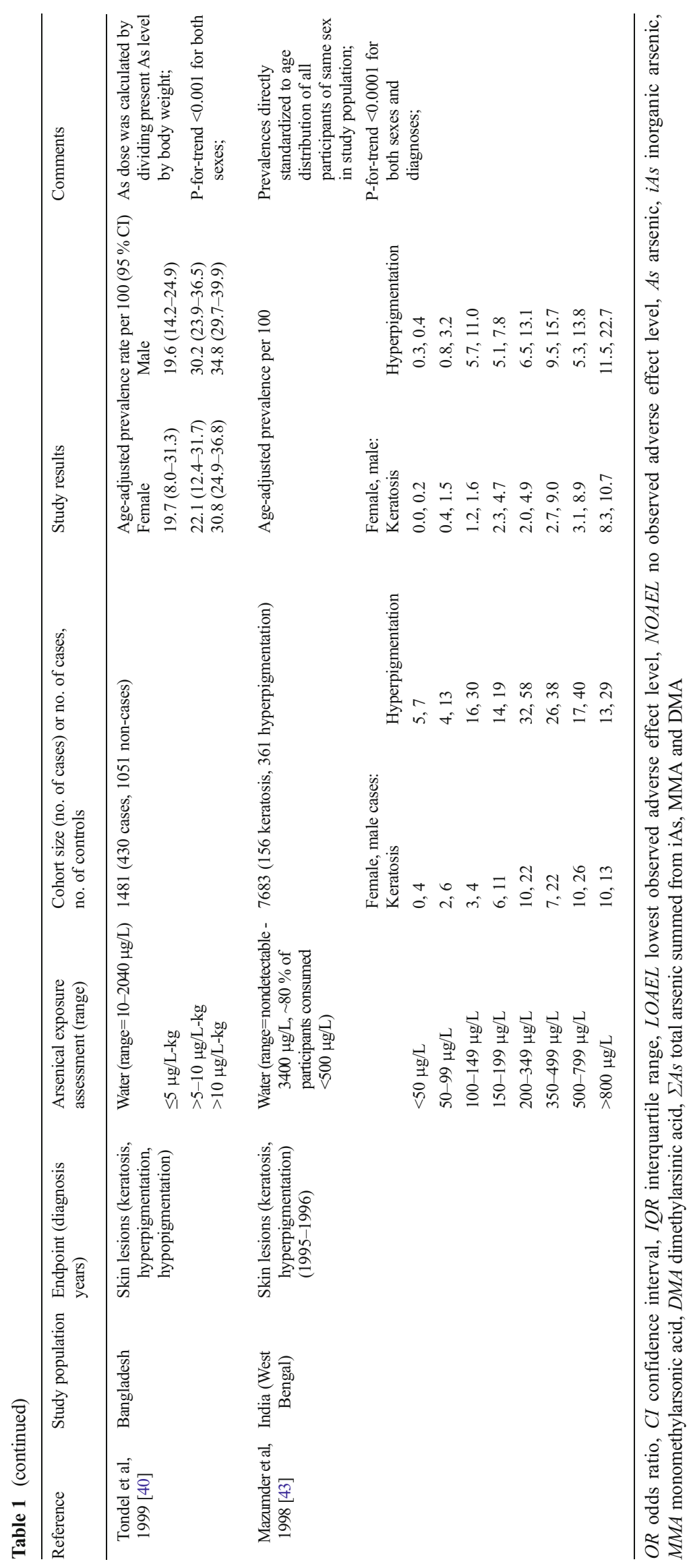




\section{a}

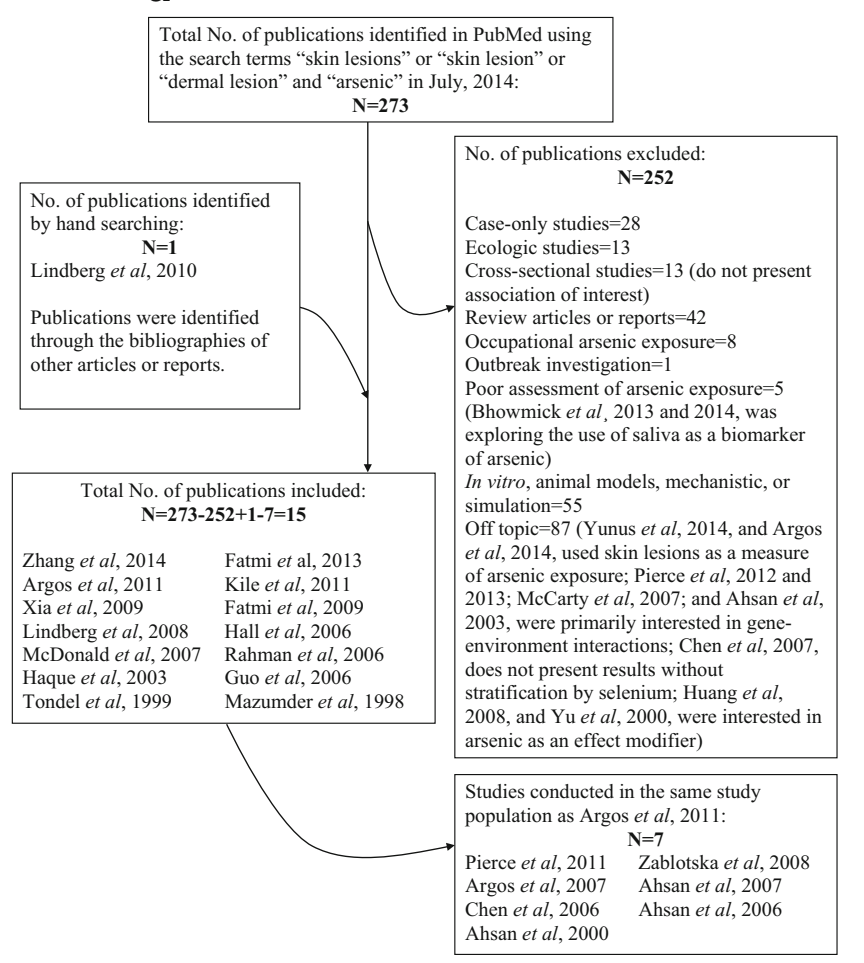

b

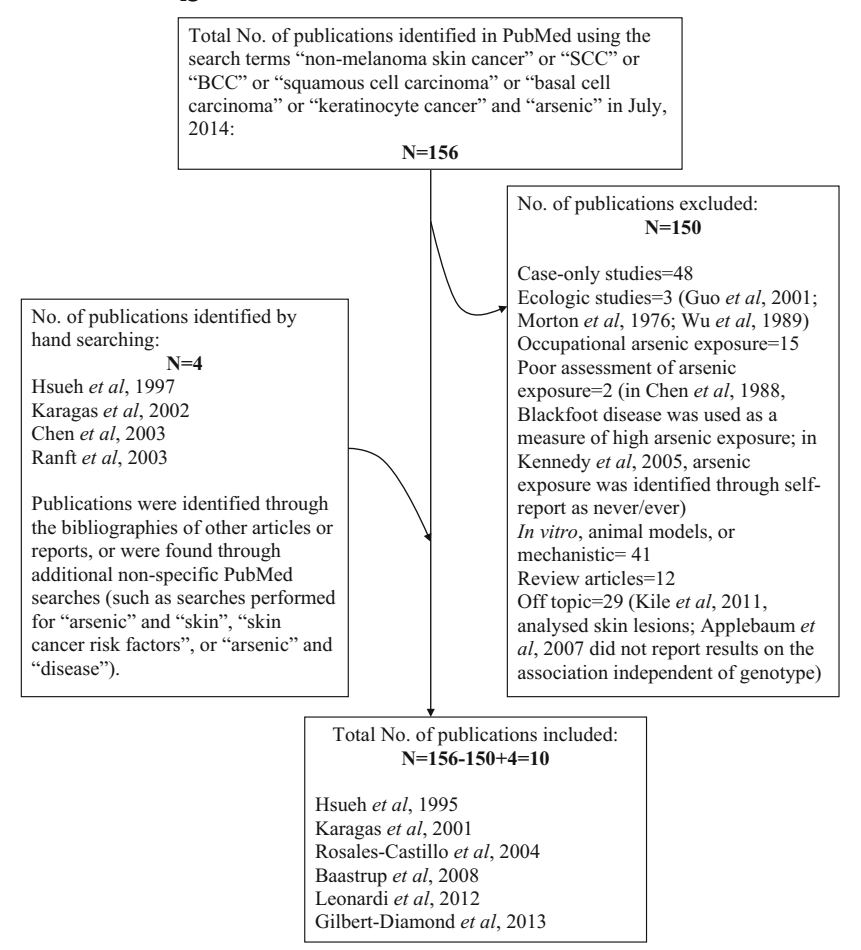

Fig. 1 a, Diagram of skin lesions and arsenic publications selection. b, Diagram of skin cancer and arsenic publications selection

\section{Results}

\section{Skin Lesions and Arsenic}

Of the 22 published studies (15 individual studies representing unique research) that evaluated the association between arsenic exposure and skin lesions, the majority were conducted within South Asian populations and the others were from China (Table 1). All publications were identified in PubMed, except for 1 study identified by a hand search (Fig. 1a). There were 13 case-control or cross-sectional studies and 2 cohort studies that met our criteria.

\section{South Asia}

A total of 9 studies were conducted in Bangladesh [32•, 33•, 34-40]. In general, a well-established dose-response relationship was evident for the association between the concentration of arsenic in drinking water and skin lesions. For the Bangladeshi population, the risk of skin lesions was reported to begin at drinking water concentrations as low as $10 \mu \mathrm{g} / \mathrm{L}[32 \bullet, 41]$. In the Health Effects of Arsenic Longitudinal Study (HEALS) in Bangladesh, there was a $70 \%$ increased risk of skin lesions for those exposed to $50-100 \mu \mathrm{g} / \mathrm{L}$ water arsenic as compared with those with $<10 \mu \mathrm{g} / \mathrm{L}$, and this risk increased monotonically with higher concentration, with more than 3-fold increased risk for the highest exposed group $(\geq 200.1 \mu \mathrm{g} / \mathrm{L})[32 \bullet]$.
Several other studies in South Asian populations reported increased risk for water arsenic [33•, 36, 38, 42, 43]. In West Bengal, India, the risk for skin lesions also began to increase with water arsenic concentrations $>50 \mu \mathrm{g} / \mathrm{L}[42]$ as had been observed in many Bangladesh studies, and prevalence estimates showed an increase in skin lesion cases also beginning around $50 \mu \mathrm{g} / \mathrm{L}$ with a significant trend of increasing prevalence as water arsenic levels increased [43]. The Sindh region of Pakistan's elevated water arsenic levels resulted in significantly increasing prevalence of skin lesions with increasing water arsenic and cumulative ingested dose or urine excretion [44, 45].

In addition to well water concentrations of arsenic, measures of urinary arsenic, urinary arsenic metabolites, and arsenical toenail concentration can inform to what extent the internal dose of arsenic drives skin lesion status [46]. In Bangladesh, numerous studies have reported increased risk of skin lesions with higher levels of urinary arsenic [32•, 33•, 34, 39]. In HEALS, creatinine-adjusted total urinary arsenic was associated with increasing risk of skin lesions in a significant trend, with those excreting the highest levels of arsenic in urine ( $>393 \mu \mathrm{g} / \mathrm{g}$ ) having 2.4-fold increased odds of skin lesions compared with those with the lowest levels of urinary arsenic [32•].

Some of these studies also evaluated modifiers of skin lesion risks. In HEALS and other study populations, skin lesion risk related to arsenic was modified by host factors including gender [47], genetic variations as described below [37], and $\operatorname{diet}[48,49]$. 


\section{China}

A case-control study conducted in the Inner Mongolia region of China reported significantly increased risk of skin lesions beginning from $5.1 \mu \mathrm{g} / \mathrm{L}$ of arsenic in well water, with increasing risk as water concentrations increased [50]. Similarly, a cross-sectional analysis of a study conducted in Inner Mongolia calculated greatly increased risk of skin lesions when exposed to $>50 \mu \mathrm{g} / \mathrm{L}$ of arsenic in water-even after adjusting for duration of exposure [51]. The dose-response trends between arsenic concentration in water and skin lesion risks are very similar to those reported for water arsenic in the HEALS cohort in Bangladesh.

\section{Skin Cancers and Arsenic}

The 10 publications identified as meeting our criteria were from 8 distinct study populations reported from 7 countries (Table 2). Two publications were derived from the same study $[52,53]$, but presented different analyses (1 categorical and 1 continuous) so are represented in Table 2 as 1 study. Two publications were conducted on different samples drawn from the same study population, and therefore are presented separately in Table $2[54,55]$. Six publications were identified from PubMed and four publications from a hand search (Fig. 1b). There were 2 cohort studies and 8 case-control studies that met our criteria.

\section{Northern Europe}

An analysis based on the prospective Diet, Cancer and Health (EPIC) study from Denmark ( $n=56,378$ persons) determined drinking water concentrations for individual cohort members by linking their addresses to average water concentrations of the water utilities serving the area [56]. For individuals who lived in residential areas served by multiple utilities, drinking water concentrations were averaged over these utilities. Data on potential confounders were collected from questionnaires at enrollment and included skin reaction to the sun, but not information on sun exposure history itself. First nonmelanoma skin cancers were identified in the cohort by linking to the Danish Cancer Registry that ascertains these malignancies; however, analyses were not performed separately for basal cell carcinomas and squamous cell carcinomas (ie, they were grouped in the analysis). Estimated water concentrations ranged from $0.05 \mu \mathrm{g} / \mathrm{L}$ to $25.3 \mu \mathrm{g} / \mathrm{L}$ with $95 \%$ of the population being at or below $2.1 \mu \mathrm{g} / \mathrm{L}$ - and thus, had very low exposure. No overall association with skin cancer was observed (IRR 0.99, $95 \% \mathrm{CI}=0.94,1.06$, per $\mu \mathrm{g} / \mathrm{L}$ increase in time-weighted average exposure since age 41 ).
Eastern Europe

A population-based case-control study in Slovakia included 264 histologically confirmed first primary NMSC registered in the region (of which $91 \%$ were basal cell carcinoma) and 286 randomly selected age and sex matched controls [57]. In a stepwise regression analysis, adjusted for urinary creatinine, sex, renal disorder, current smoking status, place of residence, self-supply with homegrown food, arsenic in house dust samples, arsenic in soil samples, and age, total urinary arsenic was higher in NMSC cases than controls $(P=0.03)$ as was inorganic urinary arsenic $(P<0.001)$ and DMA $(P=$ $0.045)$. Exposure to arsenic in this population was largely due to emissions from a coal burning power plant, and arsenic in drinking water was estimated to be relatively low [58].

The Arsenic Health Risk Assessment and Molecular Epidemiology (ASHRAM) study was a larger casecontrol study of 529 newly diagnosed, histologically confirmed basal cell skin cancer cases identified from hospital pathologists and 540 hospital (mostly general surgery, orthopedic, and trauma, eg, appendicitis, abdominal hernia, duodenal ulcer, cholelithiasis, or fracture in-patients) controls from Hungary, Romania, and Slovakia [59]. An odds ratio of 1.18 (95\% CI= $1.08,1.28)$ was associated with each $10 \mu \mathrm{g} / \mathrm{L}$ increase in average lifetime drinking water concentration of inorganic arsenic.

\section{Taiwan}

In a cross-sectional study of 1081 individuals from the southwest of Taiwan, skin cancer prevalence was associated with average drinking water concentrations in their village of residence and cumulative drinking water arsenic exposure, with evidence of a dose-response relationship [54]. Similar trends were observed with incident skin cancer occurrences $(n=33)$ during the follow-up period [55]. Also in southwest Taiwan, a hospital-based case-control study included 76 newly diagnosed NMSC cases with histologically confirmed Bowen's disease $(29.2 \%)$, basal cell carcinoma $(33.3 \%)$ or squamous cell carcinoma (47.2\%) from National Cheng-Kung University Hospital and 224 hospital controls (with diagnoses of fractures or cataracts) [60]. Urinary arsenic measurements were taken along with estimates of cumulative arsenic exposure derived from the average artesian well water concentration in their village of residence 30 years ago and duration of consuming that water. While no association was observed with NMSC and total urinary arsenic, an increasing trend was found with cumulative arsenic exposure ( $P$ for trend $=0.007)$. 


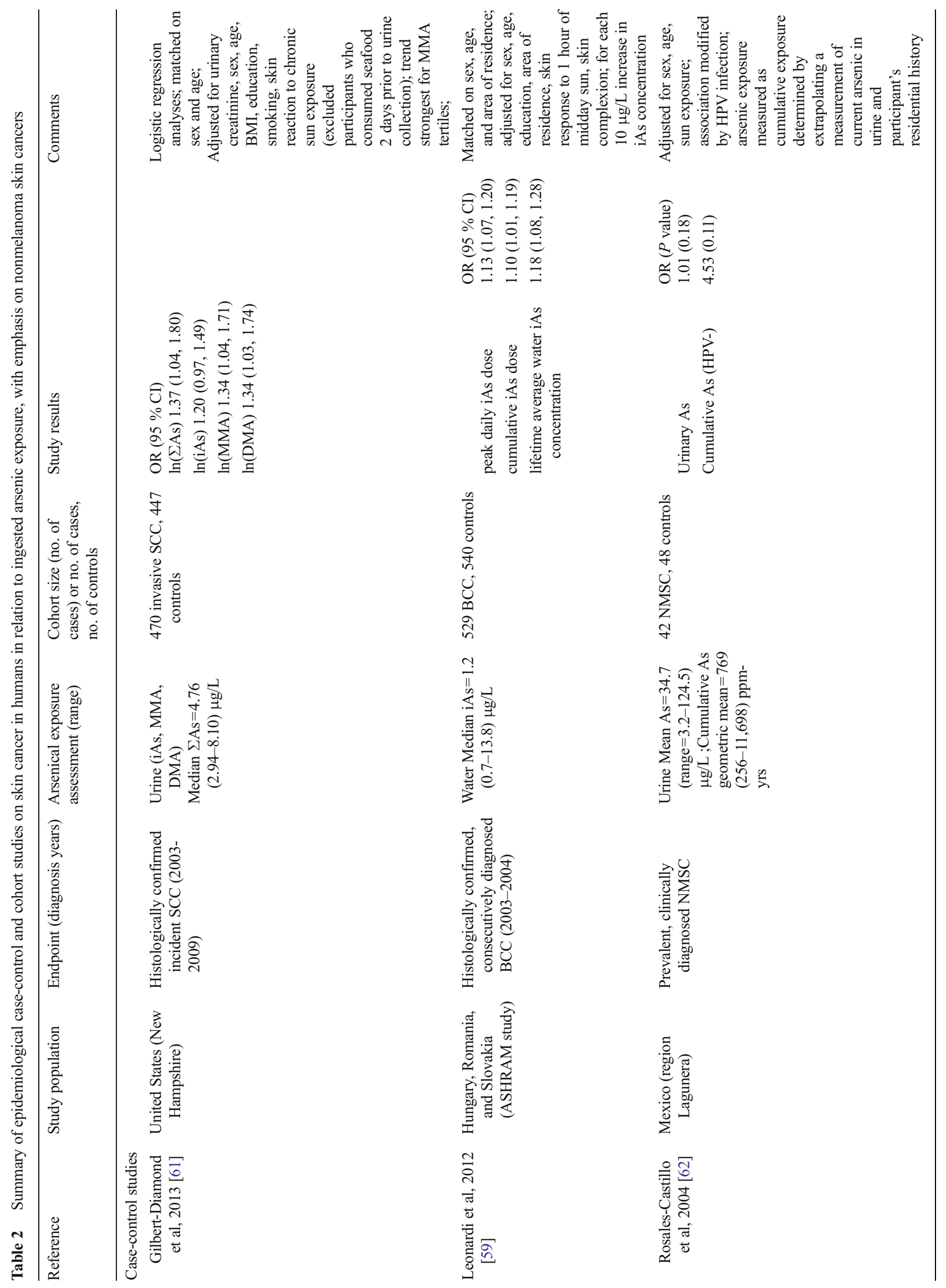




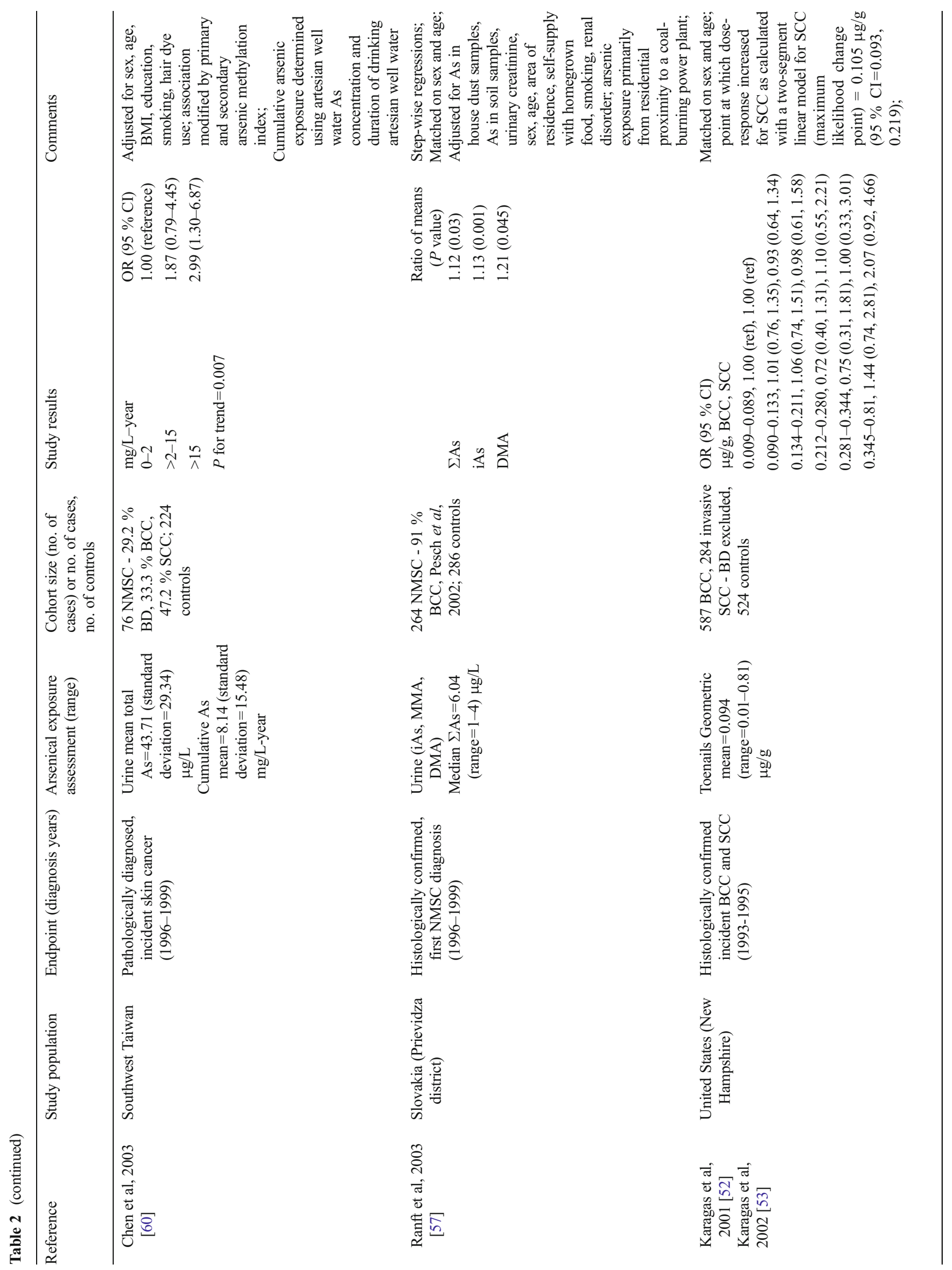




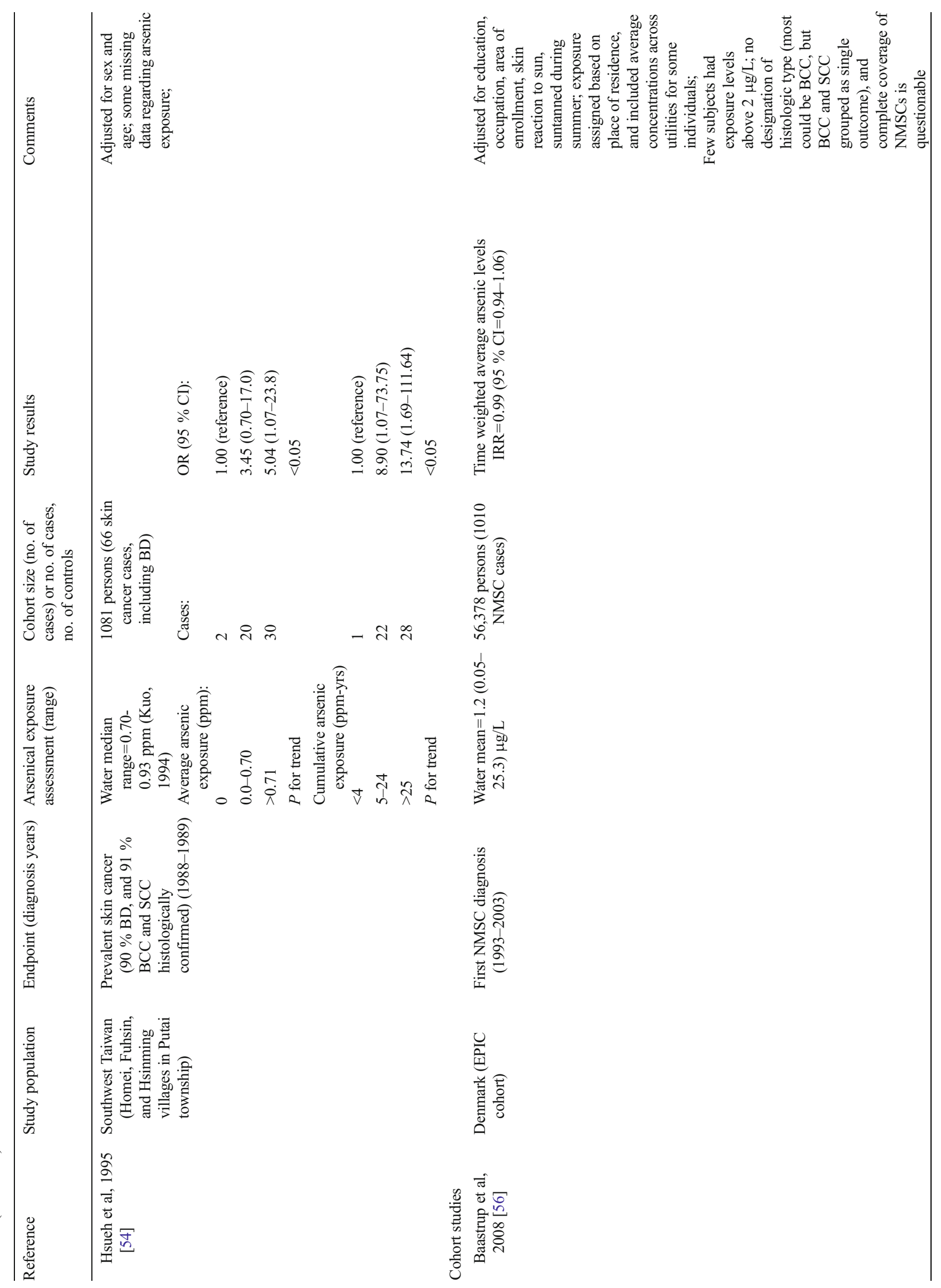




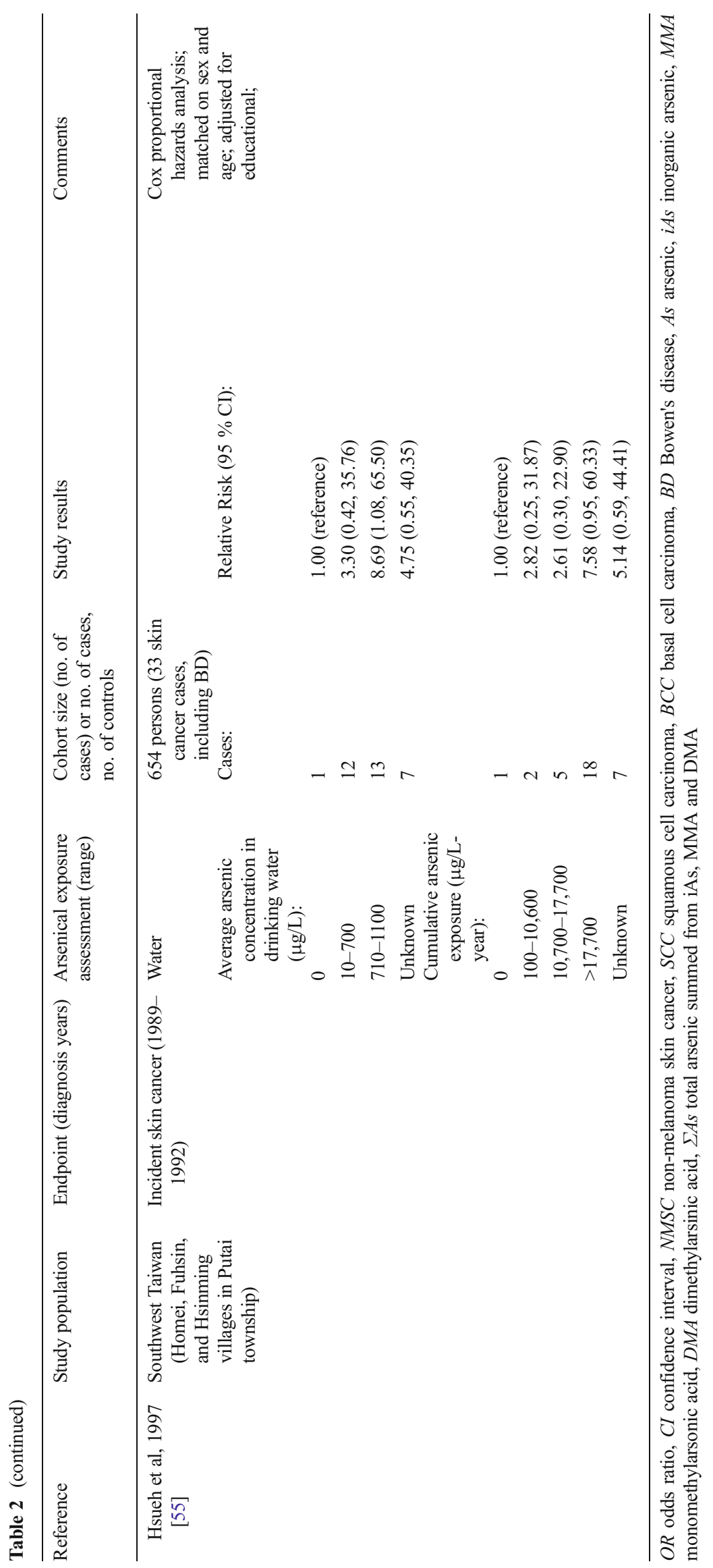




\section{USA}

In a population-based case-control study of incident basal cell $(n=587)$ and invasive squamous cell skin cancers $(n=284)$ and 524 age- and sex-matched controls from New Hampshire, USA, there was evidence of an increased risk of invasive squamous cell carcinoma $(\mathrm{OR}=2.07,95 \% \mathrm{CI}=0.92,4.66)$ and to a lesser extent basal cell carcinoma of the skin $(\mathrm{OR}=$ $1.44,95 \% \mathrm{CI}=0.74,2.81)$ among those with the highest levels of toenail arsenic concentration compared with those with the lowest levels of toenail arsenic concentration [52]. Fitting a 2-segment linear model with continuous toenail arsenic concentrations, a dose-response relationship was observed above the change-point of $0.105 \mu \mathrm{g} / \mathrm{g}$ that translated to $1-2 \mu \mathrm{g} / \mathrm{L}$ in drinking water [53]. A large proportion of the study population $(30 \%-40 \%)$ had a private, unregulated water system at their place of residence, with over $10 \%$ of the private systems containing arsenic above $10 \mu \mathrm{g} / \mathrm{L}$. A subsequent population-based case-control study from New Hampshire specifically investigated squamous cell carcinomas of the skin using urinary arsenic detection. In this study, a linear dose-related increase was observed with total urinary arsenic (excluding arsenobetaine) $(\mathrm{OR}=1.37,95 \% \mathrm{CI}=1.04$, 1.80 per unit increase of ln-transformed concentrations of arsenic). There was an increasing trend in the odds ratios for SCC with each urinary fraction (absolute concentrations of iAs; monomethylated arsenic species, MMA; dimethylated arsenic species, DMA), with the strongest association for MMA [61].

\section{Mexico}

A small dermatology clinic-based case-control study from Lagunera, Mexico involved 42 prevalent clinically diagnosed NMSC cases and 48 controls [62]. Individual arsenic exposure was determined by urinary arsenic and historic exposures using drinking water arsenic concentrations for their place of residence multiplied by the number of years they lived there. The investigators hypothesized that human papillomavirus (HPV) infection might contribute to NMSC risk among those chronically exposed to arsenic as a result of enhanced viral susceptibility to infection consequent to arsenic-induced immunosuppression. While they found no association with urinary arsenic or historic exposure among those seronegative for HPV 16, a higher odds ratio was found among those with high historic arsenic exposure who were HPV 16 positive ( $\mathrm{OR}=16.5, P=0.001,95 \%$ $\mathrm{CI}=2.97,91.75)$ when compared with those who were HPV 16 negative and had low arsenic exposure. This subgroup finding however, was based on very small stratum sizes, and may have been due to chance, particularly since HPV16 is not among the cutaneous HPVs (eg, reviewed in Farzan et al. 2013 [63]).
Interactions with Arsenic Metabolites or Genetic Polymorphisms in ASMT (Arsenite Methyltransferase)

Several epidemiological studies have reported associations between arsenic metabolite percentages measured in urine and risk for arsenical skin lesions [33•, 35, 37, 64, 65]. More specifically, higher MMA\% (and/or lower DMA\%) in urine have been related to reduced methylation capacity and an increased risk of skin lesions [37]. This suggests that low arsenic metabolism capacity is a risk factor for arsenic toxicity because individuals with low-capacity genotypes will retain more arsenic in the body. These findings further imply that metabolism capacity (and genetic variants that influence this capacity) may interact with arsenic exposure to influence skin lesion risk. These results also are consistent with in vitro and animal studies that provide evidence that MMA is a potential driver of arsenical skin lesions risk [37].

In Bangladesh, a case-control study found participants excreting higher proportions of MMA (>12\%) but lower DMA proportions $(<76 \%)$ to be at significantly higher risk of skin lesions [35], and the increased risk associated with higher MMA\% (starting around $13 \%$ ) was also seen in another study conducted in Bangladesh [37]. A casecontrol study from Bangladesh used path analysis to determine that the odds of skin lesions were significantly associated with $\log _{10} \mathrm{MMA} \%$, but found no association with DMA [33•]. A small Taiwanese case-control study of 26 skin lesion patients with gender- and age-matched controls indicated that participants with high MMA\% (more than $15.5 \%$ ) had an odds ratio of skin lesions of 5.5, compared with those with low MMA\%, and those with low DMA\% (less than $72.2 \%$ ) had an odds ratio of 3.25 , compared with those with high DMA\% [66]. A Mexican crosssectional study of 104 residents of neighborhoods in close proximity to mining operations and contaminated groundwater found a difference in the mean percentage of MMA in the urine among As-exposed subjects, with residents displaying skin lesions having $7.7 \%$ MMA, and residents without lesions having $5.9 \%(P=0.072)$ [64]. Yet another study conducted in the Huhhot Basin of China found the proportion of arsenic metabolites within urine samples to influence risk of skin lesions, with lowered arsenic methylation capacity (ie, lower DMA\% and higher MMA\%) suggested to increase the risk of arsenic-induced skin lesions [67].

The most prominent example of genetic variation influencing arsenic metabolism capacity is the 10q24.32 locus, which harbors the AS3MT gene (encoding the arsenite methyltransferase enzyme). Genetic variants in this region have shown consistent association with arsenic metabolism capacity across several populations (reviewed in Agusa et al [14]). A 
recent genome-wide association study (GWAS) of Bangladeshi individuals confirmed this finding and provided evidence of 2 independent association signals in this region, represented by rs9527 and rs11191527 [15].

Recent studies have reported associations between these 10q24.32 metabolism-related SNPs and skin lesion risk. A Bangladeshi study of 2483 skin lesion cases and 2857 controls demonstrated independent association for both metabolismrelated 10q24.32 SNPs (rs9527 and rs11191527) and skin lesions status, with the high-methylation capacity alleles being associated with decreased risk [16•]. These SNPs also showed evidence of interaction with arsenic exposure to influence skin lesions risk, with the effect of arsenic being stronger among individuals with low metabolism capacity alleles [16•]. Similarly, in a study of arsenic-exposed Mexican individuals (71 skin lesions cases and 51 controls), the low-capacity allele of 10q234.32 SNP rs11191439 was associated with decreased DMA\% and increased skin lesions risk. rs11191439 is a nonsynonymous AS3MT SNP (Met287Thr) that is in moderate to strong linkage disequilibrium with $\mathrm{rs} 9527\left(\mathrm{r}^{2}\right.$ of 0.29 to 0.95 , depending on population). In contrast to these studies, data from 229 skin lesions cases and 199 controls sampled from an arsenic-exposed Indian population showed no association between AS3MT SNP rs11191439 (Met287Thr) and skin lesions status [17]. Aside from 10q24.32, no other genomic regions have shown consistent association with arsenic metabolism capacity or skin lesion risk across multiple studies (reviewed in [18]). Also, no additional regions were identified in the GWAS setting $[15,16 \bullet]$.

To date, we know of no studies that have specifically evaluated associations or SNP-arsenic interactions for 10q24.32 variants in relation to skin cancer risk. However, there is some, albeit inconsistent evidence that arsenic metabolism may modify risk of skin cancer. For example, in a study from Slovakia, the ratio of inorganic to organic arsenic calculated as iAs/(MMA + DMA) was lower $(P<0.05)$ amongst cases compared with controls [58]. Likewise, in the ASHRAM study, the association between urinary iAs and skin cancer was modified by participants' ability to metabolize iAs, with participants below the median of DMA $\%$ or above the median MMA\% having greater risks [59]. One study from Taiwan found an association between skin cancer cases and a lower ratio of DMA/MMA but higher ratio of MMA/(AsIII + AsV) when compared with controls, suggesting cases differ from controls in their arsenic methylation capability [55]. In a case-control study from Taiwan conducted by Chen et al. 2003, a low DMA to MMA ratio was positively associated with skin cancer in participants with high cumulative arsenic exposure [60]. In contrast, in the US study reported by Gilbert-Diamond et al. 2011, while a strong association was observed for urinary MMA, the ratios or percentages of the metabolites did not appear to be related to risk of squamous cell carcinoma [61].

\section{Conclusions}

Our review of the literature examined lower exposure levels of arsenic than reviewed previously. In aggregate, clear dose-related trends have been observed for arsenic-related skin lesions at levels below $100 \mu \mathrm{g} / \mathrm{L}$ in populations from South Asia and China. The evidence for arsenic exposure and skin cancer (specifically keratinocyte cancers) also suggests a similar dose-related trend, including evidence from South Asia, Taiwan, Mexico, Eastern Europe, and the USA. As the impact on skin cancer may differ by histologic type, in future work it is critical to evaluate specific histologic types of lesions as well as measure exposure using sensitive markers, such as biomarkers. As emerging data indicates a role for genetic variation in arsenic metabolism, this also will be an important avenue of evaluation - particularly for skin cancers, for which attention has not yet focused on genetic variation in arsenic metabolism genes. Genetic variants that influence cellular defense against arsenic toxicity, as opposed to arsenic metabolism, could also interact with arsenic exposure to influence skin lesions or skin cancer risk. While no such variants have been identified to date, additional target SNP and large GWAS studies (and genome-wide GxE studies) of arsenic-related skin lesions and malignancies could facilitate the discovery of additional variants that modify the effect of arsenic disease. In summary, our review highlights the need to perform studies of arsenic exposure that estimate health risks at concentrations around the current WHO guideline of $10 \mu \mathrm{g} / \mathrm{L}$, and that the investigation of skin lesions and skin cancers may be especially helpful in informing these risks.

Acknowledgments Funding was provided in part by R01 CA057494 and R01CA107431 from the National Cancer Institute and R01 ES020506, R01 ES023834, P42 ES007373 and P42ES010349 from the National Institute of Environmental Health Sciences of the National Institutes of Health.

\section{Compliance with Ethics Guidelines}

Conflict of Interest Margaret R. Karagas, Anala Gossai, Brandon Pierce, and Habibul Ahsan declare that they have no conflict of interest.

Human and Animal Rights and Informed Consent This article does not contain any studies with human or animal subjects performed by any of the authors.

\section{References}

Papers of particular interest, published recently, have been highlighted as:

- Of importance

1. Saha KC. Diagnosis of arsenicosis. J Environ Sci Health B. 2003;38(1):255-72. 
2. Haque R, Mazumder DN, Samanta S, Ghosh N, Kalman D, Smith $\mathrm{MM}$, et al. Arsenic in drinking water and skin lesions: doseresponse data from West Bengal. India Epidemiol. 2003;14(2): 174-82. doi:10.1097/01.ede.0000040361.55051.54.

3. Ghosh P, Banerjee M, De Chaudhuri S, Chowdhury R, Das JK, Mukherjee A, et al. Comparison of health effects between individuals with and without skin lesions in the population exposed to arsenic through drinking water in West Bengal, India. J Expo Sci Environ Epidemiol. 2007;17(3):215-23. doi:10.1038/sj.jes. 7500510 .

4. Saha K. Review of arsenicosis in west Bengal, India - a clinical perspective. Crit Rev Environ Sci Technol. 2003;33(2):127-63.

5. Saha KC. Diagnosis of arsenicosis. J Environ Sci Health A. 2003;38(1):255-72.

6. Arsenic and Arsenic Compounds. . Lyon, France: WHO, International Agency for Research on Cancer. 1987.

7. IARC Working Group on the Evaluation of Carcinogenic Risks to Humans. Some drinking-water disinfectants and contaminants, including arsenic. IARC monographs on the evaluation of carcinogenic risks to humans/World Health Organization, International Agency for Research on. Cancer. 2004;84:1.

8. International Agency for Research on Cancer Special Report: Policy, A review of Human Carcinogens-Part C: Metals, Arsenic, Dusts, and Fibres. Lyon, France: IARC Press; 2009.

9. Tseng W, Chu HM, How S, Fong J, Lin C, Yeh S. Prevalence of skin cancer in an endemic area of chronic arsenicism in Taiwan. J Natl Cancer Inst. 1968;40(3):453-63.

10. Neubauer O. Arsenical cancer: a review. Br J Cancer. 1947;1(2): 192 .

11. Yeh S, How S, Lin C. Arsenical cancer of skin: histologic study with special reference to Bowen's disease. Cancer. 1968;21(2):312-39.

12. Neumann E, Schwank R. Multiple malignant and benign epidermal and dermal tumours following arsenic. Acta Derm Venereol. 1960;40:400-9.

13. Beane Freeman LE, Dennis LK, Lynch CF, Thorne PS, Just CL. Toenail arsenic content and cutaneous melanoma in Iowa. Am J Epidemiol. 2004;160(7):679-87. doi:10.1093/aje/kwh267160/7/679.

14. Agusa T, Fujihara J, Takeshita H, Iwata H. Individual Variations in inorganic arsenic metabolism associated with AS3MT genetic polymorphisms. Int J Mol Sci. 2011;12(4):2351-82. doi:10.3390/ ijms12042351ijms-12-02351.

15. Pierce BL, Kibriya MG, Tong L, Jasmine F, Argos M, Roy S, et al. Genome-wide association study identifies chromosome 10q24.32 variants associated with arsenic metabolism and toxicity phenotypes in Bangladesh. PLoS Genet. 2012;8(2):e1002522. doi:10. 1371/journal.pgen.1002522PGENETICS-D-11-02123.

16. Pierce BL, Tong L, Argos M, Gao J, Farzana J, Roy S, et al. Arsenic metabolism efficiency has a causal role in arsenic toxicity: mendelian randomization and gene-environment interaction. Int $\mathrm{J}$ Epidemiol. 2013;42(6):1862-71. doi:10.1093/ije/dyt182. This study demonstrated an interaction between arsenic exposure and 10q24.32 (AS3MT) genotype among Bangladeshi individuals, with exposure showing a stronger association with skin lesion risk among individuals with the low metabolism efficiency genotype.

17. De Chaudhuri S, Ghosh P, Sarma N, Majumdar P, Sau TJ, Basu S, et al. Genetic variants associated with arsenic susceptibility: study of purine nucleoside phosphorylase, arsenic (+3) methyltransferase, and glutathione S-transferase omega genes. Environ Health Perspect. 2008;116(4):501-5. doi:10.1289/ehp.10581.

18. Hernandez A, Marcos R. Genetic variations associated with interindividual sensitivity in the response to arsenic exposure. Pharmacogenomics. 2008;9(8):1113-32. doi:10.2217/14622416.9. 8.1113

19. World Health Organization. Arsenic in drinking-water: background document for development of WHO guidelines for drinking-water quality. 2003.
20. Tsai S-M, Wang T-N, Ko Y-C. Mortality for certain diseases in areas with high levels of arsenic in drinking water. Arch Environ Health. 1999;54(3):186-93.

21. Chen C-J, Chuang Y-C, Lin T-M, Wu H-Y. Malignant neoplasms among residents of a blackfoot disease-endemic area in Taiwan: high-arsenic artesian well water and cancers. Cancer Res. 1985;45(11 Part 2):5895-9.

22. Wu M-M, Kuo T-L, Hwang Y-H, Chen C-J. Dose-response relation between arsenic concentration in well water and mortality from cancers and vascular diseases. Am J Epidemiol. 1989;130(6): 1123-32.

23. Tseng W-P. Effects and dose-response relationships of skin cancer and blackfoot disease with arsenic. Environ Health Perspect. 1977;19:109.

24. Tseng W-P. Blackfoot disease in Taiwan: a 30-year follow-up study. Angiology. 1989;40(6):547-58.

25. Zaldívar R. Arsenic contamination of drinking water and foodstuffs causing endemic chronic poisoning. Beitr Pathol. 1974;151(4): 384-400.

26. Mitra AK, Bose BK, Kabir H, Das BK, Hussain M. Arsenic-related health problems among hospital patients in southern Bangladesh. J Health Pop Nutr. 2002:198-204.

27. Francesconi KA, Tanggaar R, McKenzie CJ, Goessler W. Arsenic metabolites in human urine after ingestion of an arsenosugar. Clin Chem. 2002;48(1):92-101.

28. Karagas MR, Tosteson TD, Blum J, Klaue B, Weiss JE, Stannard V, et al. Measurement of low levels of arsenic exposure: a comparison of water and toenail concentrations. Am J Epidemiol. 2000;152(1): 84-90.

29. Cuzick J, Evans S, Gillman M, Price Evans DA. Medicinal arsenic and internal malignancies. Br J Cancer. 1982;45(6): 904-11.

30. Scientific Opinion on Arsenic in Food. European Food Safety Authority: panel on Contaminants in the Food Chain (CONTAM). 2009;10:1351.

31. Critical Aspects of EPA's IRIS Assessment of Inorganic Arsenic: Interim Report. The National Academies Press; 2014.

32. Argos M, Kalra T, Pierce BL, Chen Y, Parvez F, Islam T, et al. A prospective study of arsenic exposure from drinking water and incidence of skin lesions in Bangladesh. Am J Epidemiol. 2011;174(2):185-94. This study provides a clear dose-response relationship between well water arsenic and skin lesion incidence in a large sample of the Bangladeshi population.

33. Kile ML, Hoffman E, Rodrigues EG, Breton CV, Quamruzzaman Q, Rahman M, et al. A pathway-based analysis of urinary arsenic metabolites and skin lesions. Am J Epidemiol. 2011;173(7):778 86. doi:10.1093/aje/kwq427. This study uses pathway analysis in a case-control study to associate the risk of skin lesions with all urinary arsenic species, simultaneously.

34. Lindberg A-L, Sohel N, Rahman M, Persson LA, Vahter M. Impact of smoking and chewing tobacco on arsenic-induced skin lesions. Environ Health Perspect. 2010;118(4):533-8.

35. Lindberg A-L, Rahman M, Persson L-Å, Vahter M. The risk of arsenic induced skin lesions in Bangladeshi men and women is affected by arsenic metabolism and the age at first exposure. Toxicol Appl Pharmacol. 2008;230(1):9-16.

36. McDonald C, Hoque R, Huda N, Cherry N. Risk of arsenic-related skin lesions in Bangladeshi villages at relatively low exposure: a report from Gonoshasthaya Kendra. Bull World Health Organ. 2007;85(9):668-73.

37. Ahsan H, Chen Y, Kibriya MG, Slavkovich V, Parvez F, Jasmine F, et al. Arsenic metabolism, genetic susceptibility, and risk of premalignant skin lesions in Bangladesh. Cancer Epidemiol Biomark Prev. 2007;16(6):1270-8.

38. Rahman M, Vahter M, Sohel N, Yunus M, Wahed MA, Streatfield $\mathrm{PK}$, et al. Arsenic exposure and age-and sex-specific risk for skin 
lesions: a population-based case-referent study in Bangladesh. Environ Health Perspect. 2006:1847-52.

39. Hall M, Chen Y, Ahsan H, Slavkovich V, Van Geen A, Parvez F, et al. Blood arsenic as a biomarker of arsenic exposure: results from a prospective study. Toxicology. 2006;225(2):225-33.

40. Tondel M, Rahman M, Magnuson A, Chowdhury IA, Faruquee $\mathrm{MH}$, Ahmad SA. The relationship of arsenic levels in drinking water and the prevalence rate of skin lesions in Bangladesh. Environ Health Perspect. 1999;107(9):727-9.

41. Ahsan H, Chen Y, Parvez F, Zablotska L, Argos M, Hussain I, et al. Arsenic exposure from drinking water and risk of premalignant skin lesions in Bangladesh: baseline results from the Health Effects of Arsenic Longitudinal Study. Am J Epidemiol. 2006;163(12):1138-48.

42. Haque R, Mazumder DG, Samanta S, Ghosh N, Kalman D, Smith $\mathrm{MM}$, et al. Arsenic in drinking water and skin lesions: doseresponse data from West Bengal, India. Epidemiology. 2003;14(2):174-82.

43. Mazumder DNG, Haque R, Ghosh N, De Binay K, Santra A, Chakraborty D, et al. Arsenic levels in drinking water and the prevalence of skin lesions in West Bengal, India. Intl J Epidemiol. 1998;27(5):871-7.

44. Fatmi Z, Azam I, Ahmed F, Kazi A, Gill AB, Kadir MM, et al. Health burden of skin lesions at low arsenic exposure through groundwater in Pakistan. Is river the source? Environ Res. 2009;109(5):575-81.

45. Fatmi Z, Abbasi IN, Ahmed M, Kazi A, Kayama F. Burden of skin lesions of arsenicosis at higher exposure through groundwater of taluka Gambat district Khairpur, Pakistan: a cross-sectional survey. Environ Geochem Health. 2013;35(3):341-6.

46. Wilhelm M, Wittsiepe J, Schrey P, Hilbig A, Kersting M. Consumption of homegrown products does not increase dietary intake of arsenic, cadmium, lead, and mercury by young children living in an industrialized area of Germany. Sci Total Environ. 2005;343(1):61-70.

47. Chen Y, Graziano JH, Parvez F, Hussain I, Momotaj H, van Geen A, et al. Modification of risk of arsenic-induced skin lesions by sunlight exposure, smoking, and occupational exposures in Bangladesh. Epidemiology. 2006;17(4):459-67.

48. Pierce BL, Argos M, Chen Y, Melkonian S, Parvez F, Islam T, et al. Arsenic exposure, dietary patterns, and skin lesion risk in Bangladesh: a prospective study. Am J Epidemiol. 2011;173(3): 345-54.

49. Zablotska LB, Chen Y, Graziano JH, Parvez F, van Geen A, Howe $\mathrm{GR}$, et al. Protective effects of $\mathrm{B}$ vitamins and antioxidants on the risk of arsenic-related skin lesions in Bangladesh. Environ Health Perspect. 2008;116:1056-62. doi:10.1289/ehp.10707.

50. Xia Y, Wade TJ, Wu K, Li Y, Ning Z, Le XC, et al. Well water arsenic exposure, arsenic induced skin-lesions and self-reported morbidity in Inner Mongolia. Intl J Environ Res Pub Health. 2009;6(3):1010-25.

51. Guo X, Fujino Y, Ye X, Liu J, Yoshimura T. Association between multi-level inorganic arsenic exposure from drinking water and skin lesions in China. Intl J Environ Res Pub Health. 2006;3(3):262-7.

52. Karagas MR, Stukel TA, Morris JS, Tosteson TD, Weiss JE, Spencer SK, et al. Skin cancer risk in relation to toenail arsenic concentrations in a US population-based case-control study. Am J Epidemiol. 2001;153(6):559-65.

53. Karagas MR, Stukel TA, Tosteson TD. Assessment of cancer risk and environmental levels of arsenic in New Hampshire. Intl J Hyg Environ Health. 2002;205(1):85-94.
54. Hsueh Y, Cheng G, Wu M, Yu H, Kuo T, Chen C. Multiple risk factors associated with arsenic-induced skin cancer: effects of chronic liver disease and malnutritional status. $\mathrm{Br} \mathrm{J}$ Cancer. 1995;71(1):109-14.

55. Hsueh Y-M, Chiou H-Y, Huang Y-L, Wu W-L, Huang C-C, Yang $\mathrm{M}-\mathrm{H}$, et al. Serum beta-carotene level, arsenic methylation capability, and incidence of skin cancer. Cancer Epidemiol Biomark Prev. 1997;6(8):589-96.

56. Baastrup R, Sorensen M, Balstrom T, Frederiksen K, Larsen CL, Tjonneland $\mathrm{A}$, et al. Arsenic in drinking-water and risk for cancer in Denmark. Environ Health Perspect. 2008;116(2):231-7. doi:10. 1289/ehp.10623.

57. Ranft U, Miskovic P, Pesch B, Jakubis P, Fabianova E, Keegan T, et al. Association between arsenic exposure from a coal-burning power plant and urinary arsenic concentrations in Prievidza District, Slovakia. Environ Health Perspect. 2003;111(7):889-94.

58. Pesch B, Ranft U, Jakubis P, Nieuwenhuijsen MJ, Hergemöller A, Unfried K, et al. Environmental arsenic exposure from a coalburning power plant as a potential risk factor for nonmelanoma skin carcinoma: results from a case-control study in the district of Prievidza, Slovakia. Am J Epidemiol. 2002;155(9):798-809.

59. Leonardi G, Vahter M, Clemens F, Goessler W, Gurzau E, Hemminki K, et al. Inorganic arsenic and basal cell carcinoma in areas of Hungary, Romania, and Slovakia: a case-control study. Environ Health Perspect. 2012;120(5):721-6. doi:10.1289/ehp. 1103534.

60. Chen Y-C, Guo Y-LL, Su H-JJ, Hsueh Y-M, Smith TJ, Ryan LM, et al. Arsenic methylation and skin cancer risk in southwestern Taiwan. J Occup Environ Med. 2003;45(3):241-8.

61. Gilbert-Diamond D, Li Z, Perry AE, Spencer SK, Gandolfi AJ, Karagas MR. A population-based case-control study of urinary arsenic species and squamous cell carcinoma in New Hampshire, USA. Environ Health Perspect. 2013;121(10):1154.

62. Rosales-Castillo JA, Acosta-Saavedra LC, Torres R, Ochoa-Fierro J, Borja-Aburto VH, Lopez-Carrillo L, et al. Arsenic exposure and human papillomavirus response in non-melanoma skin cancer Mexican patients: a pilot study. Intl Arch Occup Environ Health. 2004;77(6):418-23. doi:10.1007/s00420-004-0527-0.

63. Farzan SF, Waterboer T, Gui J, Nelson HH, Li Z, Michael KM, et al. Cutaneous alpha, beta and gamma human papillomaviruses in relation to squamous cell carcinoma of the skin: a population-based study. Intl J Cancer. 2013;133(7):1713-20.

64. Valenzuela OL, Borja-Aburto VH, Garcia-Vargas GG, CruzGonzalez MB, Garcia-Montalvo EA, Calderon-Aranda ES, et al. Urinary trivalent methylated arsenic species in a population chronically exposed to inorganic arsenic. Environ Health Perspect. 2005: $250-4$.

65. Gao J, Yu J, Yang L. Urinary arsenic metabolites of subjects exposed to elevated arsenic present in coal in Shaanxi Province, China. Int J Environ Res Publ Health. 2011;8(6):1991-2008. doi: 10.3390/ijerph8061991ijerph-08-01991.

66. Yu RC, Hsu K-H, Chen C-J, Froines JR. Arsenic methylation capacity and skin cancer. Cancer Epidemiol Biomark Prev. 2000;9(11):1259-62.

67. Zhang Q, Wang D, Zheng Q, Zheng Y, Wang H, Xu Y, et al. Joint effects of urinary arsenic methylation capacity with potential modifiers on arsenicosis: a cross-sectional study from an endemic arsenism area in Huhhot Basin, northern China. Environ Res. 2014;132:281-9. 